Uniwersytet Przyrodniczo-

Humanistyczny w Siedlcach

Siedlce University of Natural

Sciences and Humanities

https://bazawiedzy.uph.edu.pl

\begin{tabular}{|l|l|}
\hline Publikacja / Publication & $\begin{array}{l}\text { Комениология XXI века как проблема гуманитарных наук, } \\
\text { Mnich Roman }\end{array}$ \\
\hline $\begin{array}{l}\text { Adres publikacji w Repozytorium } \\
\begin{array}{l}\text { URL / Publication address in } \\
\text { Repository }\end{array}\end{array}$ & https:/bazawiedzy.uph.edu.pl/info/article/UPH0e1863f3462d44138c8b97ac6779ce4b/ \\
\hline $\begin{array}{l}\text { Data opublikowania w Repozytorium } \\
\text { / Deposited in Repository on }\end{array}$ & 22 paź 2021 \\
\hline Rodzaj licencji / Type of licence & Attribution-NoDerivs (CC BY-ND 3.0) ○ \\
\hline Cytuj tę wersję / Cite this version & $\begin{array}{l}\text { Mnich Roman: Комениология XXI века как проблема гуманитарных наук, } \\
\text { Siedleckie Zeszyty Котепiologiczne seria РEDAGOGIKA, по. 6, 2019, pp. 43-53 }\end{array}$ \\
\hline
\end{tabular}


Roman Mnich

ORCID: 0000-0003-3384-2821

Uniwersytet Warszawski

Wydział Lingwistyki Stosowanej

\title{
КОМЕНИОЛОГИЯ ХХІ ВЕКА КАК ПРОБЛЕМА ГУМАНИТАРНЫХ НАУК
}

\section{COMENIUS STUDIES AS A PROBLEM OF HUMANITIES}

DOI: $10.5604 / 01.3001 .0013 .6243$

\begin{abstract}
Аннотация: В статье рассмотрена комениология как специальная гуманитарная наука, возникшая в Европе в XX веке. Автор останавливается на трёх аспектах заявленной проблемы: 1) место комениологии в системе гуманитарных наук в XX веке, 2) две существующие сегодня концепции комениологии как науки, 3) проблемы и парадоксы комениологии в отдельных европейских странах (Германия, Чехия, Польша, Россия и Украина), связанные с отношением Я.А. Коменского к этим странам и с самой комениологией как интердисциплинарной наукой.
\end{abstract}

Ключевые слова: комениология, гуманитарные науки, интердисциплинарность

Abstract: The article discusses Comenius Studies (comeniology) as a special research area that shaped in Europe in the twentieth century. The author dwells on three aspects of the stated problem: 1) the place of Comenius Studies among the humanities in the twentieth century; 2) two existing concepts of comeniology; 3) problems and paradoxes of Comenius Studies in selected European countries (Germany, Czech Republic, Poland, Russia, and Ukraine), which related to the attitude of Comenius to these countries and to Comenius Studies itself as an interdisciplinary area.

Keywords: Comenius studies, humanities, interdisciplinarity

Моё участие в этом томе, посвящённом комениологии как науке, оправдано моим многолетним сотрудничеством с профессор Барбарой Ситарской, разговорами, спорами и дискуссиями, связанными с изучением жизни и творчества Яна Амоса Коменского

В наше время этот чешский учёный всё чаще изучается не только и не столько как педагог, но прежде всего - как величайший мыслительсистематизатор эпохи европейского барокко, теолог и политик. А сама 
педагогика Я.А. Коменского - как бы мы её не оценивали - была лишь частью его учения о человеке, о месте человека на земле, о сущности и смысле человеческой жизни. Таким образом то, что мы понимаем под словом педагогика у Я.А. Коменского, то есть философия обучения и воспитания человека, по существу своему стала философией жизни вариантом теологического экзистенциализма в Европе XVII века.

Многочисленные сегодняшние публикации, посвящённые Я.А. Коменскому, особенно начинающих комениологов, как правило, не учитывают уже многовековой комениологической традиции, существующей библиографии и уже опубликованных исследований. В зависимости от того, какие задачи ставит себе сегодня каждый, кто собирается написать научный текст о чешском учёном, а также от того, как мы будем смотреть на саму комениологию как науку, мы можем говорить о двух путях исследования. В одном случае, обращение к Я.А. Коменскому является лишь поводом для размышлений о других, более существенных для отдельных исследователей проблем (европейское барокко, политика в Европе в XVII века, история протестантизма, теологические споры в истории Европы в контексте экуменизма и так далее). В других случаях, исследователи обращаются к Я.А. Коменскому ради него само, ради того, чтобы глубже и лучше понять этого человека, его мыли и идеи. И в первом, и в другом случае мы должны учитывать, что на пути изучения жизни и текстов Я.А. Коменского и связанных с ним проблем, перед нами уже были десятки (ежели не сотни) исследователей. Наша задача в таком случае состоит в том, чтобы, учитывая существующий опыт, определить то новое, что мы можем сказать о чешском педагоге, или же те новые аспекты, какими поворачивается творчество Я.А. Коменского к современному человеку в XXI веке.

В русле приведённых мыслей весьма важной предстаёт задача научного определения комениологии как дисциплины или как системы знаний в области гуманитарных наук. При этом не дискутируется, конечно, серьёзное отношение самого Я.А. Коменского к точным наукам, но поскольку оно у чешского мыслителя было полностью подчинено теологии, то и сами точные науки в системе взглядов Я.А. Коменского составляли только часть его гуманитарного мировоззрения. Поэтому есть смысл рассматривать все идеи этого видного теолога, философа и педагога в границах именно гуманитарного знания, а саму комениологию как часть гуманитарных наук. 
В том развитии гуманитарных наук, которое описывала монография Ханса-Георга Гадамера Истина и метод в 1966 году и которое она же предопределила на вторую половину XX века, прослеживалась давняя немецкая традиция размежевания гуманитарных и точных наук по признаку методологии и точности (так называемой научности). Х.-Г. Гадамер, проблематизируя вопрос о методе в гуманитарных науках, предлагал совершенно по-другому смотреть на проблему человеческого опыта, который для немецкого учёного был связан с вопросом о понимании как феномене, определяющим экзистенциальную сущность человека. Таким образом, именно проблема понимания во всех его измерениях стала основополагающей для гуманитарных наук в XX веке, которые все чаще обращались к традиции гуманитарного знания. Проблема понимания в концепции Х.-Г. Гадамера расширялась и на новые области в развитии гуманитарных наук, в том числе и те, которые были связаны с изучением классического европейского наследия от античности до современности. И оказывалось, что самым важным при изучении наследия является именно впорос о понимании, о том, как мы понимает тексты и правильно ли мы их понимаем. Именно в текстах запечатлевалась экзистенциальная сущность человека: его понимание мира, в котором он живёт (природа) и его понимание мира, который он создает (цивилизация и культура).

Понятно, что обозначенная здесь экзистенциальная сущность человека ярче всего проявляет себя в творчестве, во всех его (творчества) направлениях: творчество литературное, художественное, философское, отчасти научное. При этом именно индивидуальное творчество отдельных видных представителей человеческой культуры всегда было огромнейшей загадкой и проблемой для изучения. Масштабность личности определяла сферу (или сферы) изучения её наследия и возможность выделения такого изучения в отдельную область, отдельную часть гуманитарных наук. В разных национальных культурах по-разному складывалась историческая ситуация, связанная с такими процессами обособления отдельной гуманитарной науки, направленной на изучение творчества одной конкретной личности. Как правило, такие науки отражают прежде всего опыт общения с художественной литературой, поэтому больше всего отдельных гуманитарных дисциплин связано с изучением жизни и творчества писателей.

Обращаясь, например, к опыту русской культуры, мы можем назвать целый ряд таких дисциплин, название которых обычно 
происходит от имени писателя, к которому (имени) прибавляется слово «ведение»: пушкиноведение, лермонтоведение, ахматоведение, достоевсковедение, булгаковедение и так далее. В русском языке весьма редки случаи образования науки, посвященной творчеству отдельного автора, с помощью латинского слова «логия». Самым известным примером может быть в этом случае шекспирология, которая однако постоянно соперничает с шекспироведением, а также в последние годы комениология.

Комениология, то есть наука о жизни и творчестве Яна Амоса Коменского (1592-1670), его влиянии на европейскую культуру в самом широком смысле этого слова, его рецепции в разных странах, обосновалась в отдельную науку сравнительно недавно. Впервые наиболее серьёзные размышления на тему истории комениологии как отдельной науки были представлены в статье Марты Бечковой (Marta Bečková) - одного из самых видных комениологов современности, долголетнего главного редактора журнала „Аcta Comeniana“. Статья М.Бечковой под названием Комениология - научная дисциплина? (Die Comeniologie - ein wissenschaftliches Fach?) была напечатана на немецком языке и, как писала сама автор, вызвана была необходимостью критического осмысления комениологии и желанием ответить на ряд вопросов, связанных с состоянием комениологии, которая понемногу становится безбрежной наукой и начинает обозначать весьма разнообразные явления (Marta Bečková 2004: 19). М. Бечкова подчёркивала, что в научной литературе о Я.А. Коменском до Второй мировой войны не встречается слово комениология, это понятие также очень редко встречается и в 50-70 годы XX века. Дальше автор обращала специальное внимание на тот факт, что само название комениология для обозначения отдельной дисциплины было впервые введено только в 1965 году чешским комениологом Йозефом Брамборой (Josef Brambora, 1904-1980), который, будучи секретарём в группе комениологов при тогдашней Чехословацкой Академии наук написал статью о комениологии для Педагогического словаря. В своём тексте Й.Брамбора писал, что комениология - это научное изучение жизни, деятельности, произведений и влияния Яна Амоса Коменского, и связывал такой подход прежде всего с научной деятельностью Яна Квачалы (Ján Kvačala, 1862-1934), который считается родоначальником комениологии. При этом, конечно же, упоминались заслуги и других исследователей жизни и творчества Я.А. Коменского, предшественников Я.Квачалы - Франтишка Палацкого 
(František Palacký, 1798-1876), Франтишка Зоубека (František Zoubek, 1832-1890), Йозефа Шмаги (Josef Šmaha, 1843-1922).

Анализируя целый ряд определений комениологии в словарях и энциклопедиях, а также и в научных работах, М. Бечкова в упоминаемой статье отдельно останавливается на парадоксальном определении коменилогии, которое мы встречаем у Антонина Шкарки (Antonín Škarka, 1906-1972). А. Шкарка, анализируя переписку Я.А. Коменского с его амстердамским издателем Петером ван ден Берге (Peter van den Berge), обратил внимание на то, что в своих письмах чешский мыслитель очень своеобразно сам комментирует свои сочинения. В свете этого факта, А.Шкарка считает, что родоначальником современной комениологии нужно считать самого Яна Амоса Коменского („Comenius - Begründer der Comerniologie").

Статья Марты Бечковой отличается той особенностью, что в ней обсуждается вопрос о комениологии как об отдельной научной дисциплине, а не просто сумме комениологических исследований (Comeniusforschung). Автор задается вопросом, чем же в сущности является сегодня комениология: научной дисциплиной, пограничной наукой, междисциплинарной общественно-научной областью, областью исследо-вания или исследовательским направлением? („Was also ist die Comeniologie: ein wissenschaftlicher Fachbereich, eine Grenzwissenschaft, ein interdisziplinärer gesellschaftswissenschaftlicher Fachbereich, ein Bereich der Forschung oder eine Forschungsrichtung?", Bečková 2004: 27).

В отличие от позиции М. Бечковой в современных комениологических исследованиях (Comeniusforschung, Comenius Studies) очень часто комениология понимается весьма расширительно и сводится в принципе ко всем публикациям, касающимся жизни и творчества Яна Амоса Коменского. Исследователи ищут начала комениологии не только в XIX веке, но и ещё раньше, связывая возникновение этой науки вообще с появлением первых публикаций о Я.А. Коменском в той или иной стране. Так, например, представлена концепция русской комениологии в публикациях Людмилы Лаптевой (Лаптева, 1991: 381-439) или польской комениологии в статье Барбары Ситарской (Sitarska, 2014: 31-61).

Бросая взгляд в прошлое, мы можем с убеждением, почти что граничащим с уверенностью, сказать, что в каждой европейской стране изучение жизни и творчества великого чешского мыслителя имело свою специфику, но не всегда итоги такого изучения в своей совокупности образовали отдельную национальную науку. Мы можем, например, 
говорить о болгарских комениологах, но вряд ли можно серьезно рассуждать на тему болгарской комениологии как отдельной дисциплины, имеющий свой научный статус в Болгарии. Конечно же, существует общая европейская комениология, частью которой являются отдельные национальные комениологии, но, повторюсь опять, далеко не в каждой стране комениология стала отдельной гуманитарной дисциплиной.

Совершенно очевидно, что если мы будем понимать комениологию как науку, имеющую прежде всего свои праксеологические цели в отдельно взятой стране, то такая наука не возникает вместе с появлением публикаций о Я.А. Коменском или же изданием его сочинений. Я специально остановился на проблеме праксеологических целей, а не других параметрах гуманитарной науки, таких, например, как метод или объект изучения. Исторический опыт свидетельствует, что методы у комениологов (даже самых выдающихся) очень часто бываю совершенно разными, а иногда и противоположными. Аналогично, объектом изучения - как это ни парадоксально - у комениологов не всегда бывает сам Ян Амос Коменский (как личность, писатель, создатель теорий и текстов, требующих постоянно обновляющейся интерпретации). Ведь комениолог может изучать эстетику барокко (на примере творчества чешского мыслителя), может изучать историю дипломатии в Европе семнадцатого века, историю европейского театра, историю религиозных движений, историю экуменизма и тому подобные явления, связывая их с текстами или личностью Яна Амоса Коменского. Но все перечисленные аспекты не создадут еще комениологии как науки до тех пор, пока не будут определены праксеологические цели такой науки в конкретном обществе.

Ярким примером в этом случае может быть немецкая комениология, начало которой можно по-разному определять, в зависимости от принятой концепции, но которая очень четко определилась именно как отдельная научная дисциплина в 1892 году, когда начал выходить специальный журнал, посвящённый Я.А. Коменскому. Это было ежемесячное периодическое издание Немецкого общества Яна Амоса Коменского - „Monatshefte der Comenius-Gesellschaft“. Уже в первом номере журнала редакция очень четко определила цели и задачи издания, считая необходимым проинформировать общественность о границах научных интересов самого общества и нового журнала (дословно: „...halten wir es für notwendig, die Grenzen näher zu umschreiben, 
welche das Arbeitsfeld der Gesellschaft und dieser Zeitschrift abstecken" „Monatshefte der Comenius-Gesellschaft", 1892: III). В этом предисловии редакции, которое называлось Наш рабочий план (Unser Arbeitsplan) достаточно подробно описывались практические цели издания и значение журнала для общества, при этом специально подчеркивалось преимущество исторических исследований в сравнении с теоретическими проблемами комениологии („Es geht daraus hervor, dass die Veröffentlichungen nicht in erster Linie der Erörterung theoretischer und grundsätzlicher Fragen, sondern geschichtlichen Untersuchungen gewidmet sein sollen“ „Monatshefte der Comenius-Gesellschaft“, 1892: IV).

Редакция, понятно, также отмечала свой интерес к жизни и творчеству Я.А. Коменского, имя которого значилось на титульной странице журнала. Этот интерес был связан с изучением жизни и творчества не только великого чешского мыслителя, но и его современников, его предшественников и преемников. Отдельно во цитируемом предисловии редакции обращалось внимание на важность изучения философских аспектов в творчестве Я.А. Коменского, особенно тех, которых были связаны с его пансофической деятельностью, направленной на преодоление национальных и конфессиональных границ и связанной с экуменическими идеями (Richter, 2013: passim). Подчёркнутый экуменической тон редакции „Monatshefte der ComeniusGesellschaft" сегодня поражает своей актуальностью, своим стремлением очертить границы комениологии и обосновать комениологию как науку, не зависимую от религиозных и национальных распрей, стремящуюся к объединению и примирению людей разных национальностей во имя общих для человечества интересов, которые связаны с именем Яна Амоса Коменского. В таком подходе к комениологии редакция видела её преимущество как настоящей науки: „Es ist im allgemeinen das Vorrecht der Wissenschaft, unbekümmert um die Gegensätze der Kirchen und Nationen zu wirken, und es liegt auf der Hand, dass eine Gesellschaft, die sich nach Comenius nennt, ihre Aufgabe ganz und gar verkennen würde, wenn sie in anderem als in versöhnendem und vereinigendem Sinne tätig sein wollte“ (,Monatshefte der Comenius-Gesellschaft", 1892: VII).

Журнал „Monatshefte der Comenius-Gesellschaft“ был тесно связан с масонской идеологией, его редактор - Людвиг Келлер (Ludwig Keller, 1849-1915) был основателем немецкого Общества Я.А. Коменского, членом нескольких масонских лож, архивариусом и историком масонства. Попутно отмечу, что близкий друг Л.Келлера и его соратник 
в обществе Я.А. Коменского - Вильгельм Бегеманн (Wilhelm Begemann, 1843-1914) был автором брошюры Коменский и масоны (Comenius und die Freimauer, 1906). В 1919 году журнал „Monatshefte der ComeniusGesellschaft“ прекратил своё существование.

По-другому выглядели задачи и цели чешской комениологии, которые были заявлены в первом чешском журнале, специальном посвящённом жизни и творчеству Я.А. Коменского - „Archiv pro badání o životě a spisech J.A. Komenského“. Журнал под таким названием выходил в 1910-1940 годах, а в обновлённом виде, начиная с 1957 года, журнал издаёт Чешская Академия наук (отдел, который специально занимается изучением жизни и творчества Я.А. Коменского и изданием его сочинений), и в таком обновлённом виде журнал называется „Acta Comeniana“ (http://komeniologie.flu.cas.cz/en/acta-comeniana-internationalreview/acta-comeniana).

Когда в 1910 году в Брно, под редакцией известного комениолога (издателя сочинений и корреспонденции Я.А. Коменского) Яны Квачалы выходил первый номер журнала „Archiv pro badání o životě a spisech J.A. Komenského“, то в слове от редакции (Prívet) подчёркивалось, что журнал служит прежде всего помощью в издании Собрания сочинений Яна Амоса Коменского. Речь шла о знаменитых („зелёных“) томах первого Полного собрания сочинений, которое, к сожалению, не было полным и которое не удалось довести до конца. Редакция журнала отмечала, что комениология, несмотря на интерес к личности чешского мыслителя и имеющуюся библиографию, является молодой наукой („Bádanie o Komenskom je pomerne mladé“ - „Archiv pro badání o životě a spisech J.A. Komenského“ 1910: 3). Поэтому основной целью журнала будут биографические и библиографические исследования, посвящённые Я.А. Коменскому в самом широком смысле: от аспектов биографии, связанных с деятельностью общины Чешских братьев, идеями Яна Гуса и Петра Хельчицкого до собственно философских и литературноисторических аспектов, связанных с творчеством Якоба Бёме, Томазо Кампанеллы, Декарта, Гельвеция и так далее (в тексте предисловия перечислялись десятки имён единомышленников и идейных противником Я.А. Коменского, названия религиозных движений в истории европейского христианства, истории педагогики и теологии, имена представителей апокалиптики и тайных обществ - „Archiv pro badání o životě a spisech J.A. Komenského“ 1910: 3-6). Среди комениологов редакция отмечала заслуги прежде всего чешских и немецких учёных 
и предлагала определённую программу дальнейший исследований текстов Я.А. Коменского.

В 1971 году Музей Я.А. Коменского в Угерском Броде начал издавать комениологический журнал - „Studia comeniana et historica“. Этот журнал отличался, с одной стороны, своей исторической направленностью, а с другой - желанием представить читателям самые важные достижения гуманитарной мысли, касающейся периода XVI-XVIII веков. Чтобы убедиться в особенностях представленной в этом журнале комениологии как гуманитарной науки, достаточно упомянуть, что на его страницах, помимо текстов Я.А. Коменского и их переводов, обсуждались книги о Шекспире, произведения Джона Донна и Балтасара Грасиана, публикации о реформации и контрреформации, о видных интеллектуалах эпохи барокко, монографии Мишеля Фуко и Михаила Барга. Как видим, в этом случае комениология как наука была представлена весьма расширительно.

Иначе определялись праксеологические цели немецкой комениологии. В 1992 году в Берлине, благодаря усилиям немецких комениологов было заново основано Немецкое общество Я.А. Коменского - Deutsche Comenius-Gesellschaft (первое общество было основано столетие назад - в 1891 году и просуществовало до времён Второй мировой войны). Немецкая комениология оформилась, таким образом, институционально, её позиции значительно усилились благодаря основанию ежегодника - „Comenius-Jahrbuch“. В предисловии к первому номеру этого ежегодника редакция определяла задачи и цели комениологии, которые сверялись по словам Томаша Масарика, сказанным о Я.А. Коменском. Эти слова цитировались как основной научный девиз ежегодника - „мы должны проверять свою собственную совесть на предмет того, исполнили ли мы или насколько исполняем завещание этого выдающегося человека“ („wir sollen das eigene Gewissen prüfen, ob wir das Vermächtnis eines so hervorragenden Mannes erfüllt haben oder erfüllen“ - „Comenius-Jahbuch“ 1993: 7).

Мне пришлось принимать участие в нескольких международных встречах комениологов в Германии, Голландии, Чехии, Польше, Украине и России. В каждой из этих стран сейчас наблюдается огромнейший интерес прежде всего к текстам Я.А. Коменского, особенно раньше не известным его сочинениям в области теологии. Польская комениология последнего времени в лице педагогов, благодаря огромному энтузиазму и усилиям Барбары Ситарской (B. Sitarska), постепенно интегрируется 
вокруг специального издания - «Siedleckie Zeszyty Komeniologiczne, seria pedagogika». Но в свете всего сказанного становится понятным, что количество комениологов не определяет статуса комениологии как науки.

Наконец, два важные замечания, которые связаны с современной комениологией и тех направлений, которые возникают уже внутри комениологии как отдельной науки. С одной стороны, сегодня, независимо от того, как исследователи жизни и творчества Яна Амоса Коменского смотрят на эпистемологические цели своей работы, становится совершенно понятным, что комениология является интердисциплинарной наукой. Поэтому исследование отдельных аспектов в наследии чешского мыслителя или интерпретация вырванных из контекста мыслей или фрагментов текста требует обязательно привлечения самого широкого контекста - исторического, теологического, литературоведческого, языкового, политического. С другой стороны, существуют принципиальные проблемы и задачи комениологии в отдельных странах. В Германии и Чехии, например, где исторически комениология возникала как наука и где формировались её основные направления, приоритетными являются издания текстов Я.А. Коменского, исторические исследования и интерпретации в области фундаментальной теологии (Schaller, 1990: 82-90), дискурсивный анализ присутствия Я.А. Коменского в современной культуре (Figurace paměti. J.A. Komenský v kulturách vzpomínání 19. a 20. Století, 2014; Klosová 2016). В Польше, безусловно важнейшей проблемой будет проблема отношения Я.А. Коменского к католической церкви и участие чешского мыслителя в антипольской коалиции в XVII веке, войне и так называемому «шведскому потопу» в Польше. В России и Украине, кроме проблемы возможных связей Я.А. Коменского с канцелярией Богдана Хмельницкого, чрезвычайно важным вопросом комениологии будет вопрос об отношении чешского учёного к православной церкви и её традициям.

Сегодняшний комениолог неминуемо сталкивается с научным вызовом комениологической традиции, в которой даже такие выдающиеся исследователи текстов Яна Амоса Коменского, как Ян Паточка признавались, что они не являются комениологами, а лишь философами и историками идей - „Der Autor dieser Zeilen ist kein Comeniologe, sondern Philosophie- und Geisteshistoriker“" (Bečková, 2004: 24). 


\section{Библиография}

"Comenius-Jahbuch“, band 1, Sankt Augustin 1993.

Bečková Marta, Die Comeniologie - ein wissenschaftliches Fach?, In: „Comenius-Jahrbuch“, Band 9-10/2001-2002, Stuttgart 2004, p. 19-28.

Figurace paměti. J.A. Komenský v kulturách vzpomínání 19. a 20. století (Lenka Řezníková a kol.), Praha 2014.

Gadamer Hans-Georg, Gesammelte Werke. Hermeneutik I: Wahrheit und Methode. Grundzüge einer philosophischen Hermeneutik, Tübingen 1990.

Giertych Jędrzej, U źródeł katastrofy dziejowej Polski: Jan Amos Komensky,

Leszno 2018.

Klosová Markéta: Divadelní svět J.A. Komenského, Praha 2016.

Lexikon der philosophischen Werke, Herausgegeben von Franko Volpi und Julian Nida-Rümeln, Stuttgart 1988.

Manfred Richter, Johann Amos Comenius und das Colloquium Charitativum von Thorn 1945. Ein Beitrag zum Ökumenismus, Siedlce 2013 (2. Auflage. Münster 2018. 546 S. - „Quellen und Darstellungen zur Geschichte Westpreußens", Nr 41).

Schaller Klaus, Comeniusforschung in der Bundesrepublik Deutschland, In: Zwanzig Jahre Comeniusforschung in Bochum, Herausgegeben von Klaus Schaller, Sankt Augustin 1990.

Sitarska Barbara, O Janie Amosie Komeńskim i poczq̨tkach komeniologii (polski, angielski, niemiecki), W: B. Sitarska (red.), Jan Amos Komeński - jego pedagogika i filozofia, „Siedleckie Zeszyty Komeniologiczne, seria pedagogika", t. II, Siedlce 2015, s. 23-44.

Sztobryn Sławomir, Polska komeniologia we współczesnych bibliotekach elektronicznych, W: B. Sitarska, R. Mnich (red.), Jan Amos Komeński a Europa XVII wieku/ Jan Amos Komenský und Europa im XVII. Jahrhundert, "Studia Comeniana Sedlcensia", t. IV, Siedlce 2012.

Volpi Franco, Dizionario delle opere filosofiche. Milano 2000.

Лаптева Людмила, Русская дореволюционная комениология, B: „Folia Historica Bohemica"15, Praha 1991.

Мельников Григорий, Изучение наследия Яна Амоса Коменского, В: „Славяноведение“, 2015, № 4. 